\title{
Genetic Background May Confer Susceptibility to PTC in Benign Multinodular Thyroid Disease
}

\author{
Sivatharsiny Thavarajah, Frank Weber \\ Department of General, Visceral and Transplantation Surgery, University Hospital Essen, Essen, Germany. \\ Email: frank.weber@uk-essen.de
}

Received September $11^{\text {th }}$, 2012; revised October $9^{\text {th }}$, 2012; accepted October $21^{\text {st }}, 2012$

\begin{abstract}
Purpose: The incidence of hyperplastic thyroid nodular disease has been consistently rising over the last decades. In addition, unsuspected papillary thyroid carcinoma (PTC) can be found in up to 34\% of patients operated for benign thyroid lesions. PTC tends to occur multi-focally and is commonly of polyclonal origin. We set out to test the hypothesis that in benign thyroid disease, a unique genetic signature can already be identified in the benign pathology, which is associated with a susceptibility of the thyroid tissue to neoplastic transformation in the context of additional growth promoting stimuli. Patients and Methods: We obtained a set of 23 samples from patients with multinodular goiter (MNG), 12 of whom also harbored an unsuspected PTC. We used global gene expression analysis to evaluate for dissimilarities in the gene expression patterns between these two groups. We also compared these patterns to the profiles of 3 normal thyroid and 7 PTC samples. Results: We were able to accurately distinguish between hyperplastic nodules of patients with multinodular goiter and those that were associated with a PTC. One of the strongest differentially expressed genes, $C D C 42$, has been implicated to respond to environmental factors such as UVB radiation and might point to novel factors contributing to PTC genesis in the setting of pre-existing benign proliferative disease. Conclusion: While the comparison between histologically identical samples cannot distinguish the two groups of goiters, unsupervised or supervised approaches allowed us to identify a molecular signature associated with PTC susceptibility in multinodular goiter.
\end{abstract}

Keywords: Multinodular Goiter; Cancer Suceptibility; Gene Expression; Papillary Thyroid Carcinoma

\section{Introduction}

The incidence of hyperplastic thyroid nodular disease (HN) such as multinodular goiter (MNG) has been consistently rising over the last decades. The frequency of thyroid nodules increases with age, and it is estimated that about $50 \%$ of all people over 60 years of age have thyroid nodules [1]. The prevalence of papillary thyroid carcinoma (PTC) and papillary microcarcinoma (PMC), the latter defined as measuring $<1 \mathrm{~cm}$ in diameter, in autopsy series also increases with age and ranges from $1 \%$ to $35.6 \%$ [2]. In addition, unsuspected PTC or PMC are frequently (up to $34 \%$ ) discovered after thyroidectomy for apparently benign nodular disease [2-4]. Furthermore, it is known that PTC often occurs as multifocal disease [2]. Shattuck et al. showed that multifocal PTC is, in general, a polyclonal disease and discussed the potential influence of environmental factors on the genesis of PTC [5]. It has been suggested previously that structural aberrations might not be the initiating events in tumorigenesis but may well be subsequent phenomena in proliferating tissue [6]. If environmental or other factors influence PTC-genesis, then it would be predicted that these factors could interact with existing genetic factors in the thyroid to result in a unique gene expression profile that would predispose to PTC. We sought to address this hypothesis in the context of multinodular goitre and unsuspected PTC. We identified a set of patients with apparently benign hyperplastic nodular disease but that harbored occult PTC and those without evidence of thyroid malignancy. If this hypothesis is true, then a distinct genetic signature might be identified already within the entire thyroid gland and/or within the hyperplastic tissue associated with unsuspected PTC. This eventually could be of great importance for the clinical management of patients with nodular thyroid disease.

\section{Patients and Methods}

\subsection{Tissue Specimens}

In total, 23 hyperplastic thyroid (MNG) tissue samples (11 from patients with multinodular goiter [MG] and 12 from patients with hyperplastic thyroid nodular dis and 
unsuspected PTC [HN + PTC]) were independently acquired for gene expression analysis in our training and validation set described below. Final histological classification for these samples was obtained from paraffinembedded tissue and evaluated by an experienced pathologist. All of these tissue sections showed hyperplastic thyroid tissue. For the samples derived from the $\mathrm{HN}+$ PTC group, we verified that we were only analyzing the regions that did not, by chance, contain PTC/PMC. In addition, a panel of 3 normal thyroid tissues and 7 invasive PTC was obtained. RNA extraction of all samples was performed for GeneChip ${ }^{\circledR}$ analysis and quantitative reverse transcription (RT)-PCR as described previously [7]. All samples were obtained as anonymized materials without linked identifiers, with the approval of the Institutional Review Board for Human Subjects’ Protection.

\subsection{RNA Extraction and Oligonucleotide Expression Micro-Array Analysis}

RNA extraction and Micro-Array analysis were performed according to the protocols previously described by us in detail [7]. In short, total RNA was isolated from $0.2 \mathrm{~g}$ of snap frozen tissue using the TRIzol Reagent (Invitrogen, Carlsbad, CA), purified with the RNeasy Kit (Qiagen, Valencia, CA) and reverse transcribed using the SuperScript II System (Invitrogen, Carlsbad, CA) and a random hexamer anchored primer (Roche, Indianapolis, IN). Samples were than hybridized to the Affymetrix HG-U133A GeneChips ${ }^{\circledR}$, which contain 22,283 probe sets. The cell intensity files (CEL) were interrogated using the Affymetrix Microarray Suite 5.0 software and BRB ArrayTools. All quality control steps have been performed as previously described [7].

\subsection{Statistical Methods}

For data analysis, we utilized the BRB-ArrayTools Version 3.6, an integrated software package for the analysis of DNA microarray data that was developed by Richard Simon and Amy Peng. We identified genes that were differentially expressed between the two classes using a random-variance model [8]. Genes were considered statistically significantly differentially expressed if their $\mathrm{p}$ value was less than 0.005 . We also performed a global test of whether the expression profiles differed between the classes by permuting the labels of which arrays corresponded to which classes. For each permutation, the $\mathrm{p}$ values were re-computed and the number of genes significant at the 0.005 level was noted. We performed supervised and unsupervised cluster analysis. On supervised approaches, we assigned each sample to a group according to its clinical/histological features (i.e. MNG and HN + PTC group). Based on the identified set of genes that showed the most significant differential ex- pression between these two groups, hierarchical clustering was performed. In contrast, for the unsupervised cluster analysis, the samples are not pre-assigned to any one group. In this manner, even unknown associations between samples might be identified. For this approach, the gene set is narrowed down based on the overall variance of one gene (i.e. genes that showed less than 1.5fold change from the mean in less than $30 \%$ of samples are excluded). After clustering of the samples, we used the R (reproducibility) measure described by Mc-Shane et al. to evaluate the robustness of the clusters [9]. The $\mathrm{R}$ measure is based on perturbing the expression data with Gaussian noise, re-clustering, and measuring the similarity of the new clusters to the original clusters. For a detailed description of the BRB-ArrayTools software package, visit http://linus.nci.nih.gov/BRB-ArrayTools.html.

\section{Results}

In order to determine whether the hyperplastic tissue from multinodular goiter with unsuspected PTC (HN + PTC) carried an expression profile that could differentiate it from MG without PTC, we characterized a defined set of samples. The "MG" group contains 11 non-functioning, multinodular hyperplasic thyroid tissues from euthyroid patients without signs of thyroid neoplasia, while the "HN + PTC" group is comprised of 12 non-functioning multinodular hyperplasic thyroid tissue from euthyroid patients who harbored an unsuspected PTC, the latter only revealed on final histology. There was no significant difference in mean age (54.5 and 60.4 years) or gender distribution between the two groups (Table 1). None of these patients had a history of external beam radiation to the head and neck for malignant disease or exposure to radiation. We identified a set of 359 genes that were differentially expressed $(\mathrm{p}<0.005)$ between the two groups (MNG and HN + PTC) at a statistically significant level. This estimated probability of randomness provided by the global test obtained a p-value of 0.011 and is thus sufficient to establish that expression profiles between two classes were different and not due to chance. Based on this set of 359 genes, the two groups (MG and HN + PTC) were accurately separated by supervised cluster analysis (Figure 1). In order to further elucidate the gene expression pattern of the 2 groups (MNG and MNG + PTC), we included the data from 7 PTC and 3 normal thyroid samples in our analysis. This way, we were able to assess if either group was more similar to normal thyroid tissue or to thyroid cancer. Based on the set of 359 genes, the 3 normal thyroid samples grouped with the benign sample group (MG) (Figure 2(a)). Similarly, clustering of an additional 7 malignant samples (PTC) showed that the HN + PTC group is more similar to the 
Table 1. Clinical description of patients with goitre and PTC.

\begin{tabular}{|c|c|c|c|c|}
\hline Sample & Age & Gender & Size $(\mathrm{cm})$ & Histology \\
\hline MNG + PTC_1 & na & na & 1.5 & $\begin{array}{c}\text { Classic } \\
\text { PTC }\end{array}$ \\
\hline MNG + PTC_2 & $\begin{array}{c}72 \\
\text { years }\end{array}$ & Male & 1.1 & FV-PTC \\
\hline MNG + PTC_3 & $\begin{array}{c}65 \\
\text { years }\end{array}$ & Female & 0.1 & $\begin{array}{c}\text { Classic } \\
\text { PTC }\end{array}$ \\
\hline MNG + PTC_4 & $\begin{array}{c}58 \\
\text { years }\end{array}$ & na & 0.3 & FV-PTC \\
\hline MNG + PTC_5 & $\begin{array}{c}69 \\
\text { years }\end{array}$ & Male & 0.4 & TCV \\
\hline MNG + PTC_6 & $\begin{array}{c}52 \\
\text { years }\end{array}$ & Female & 0.1 & $\begin{array}{c}\text { Classic } \\
\text { PTC }\end{array}$ \\
\hline MNG + PTC_7 & $\begin{array}{c}69 \\
\text { years }\end{array}$ & na & $\begin{array}{c}0.5 \\
\text { (multifocal) }\end{array}$ & $\begin{array}{c}\text { Classic } \\
\text { PTC }\end{array}$ \\
\hline MNG + PTC_8 & $\begin{array}{c}42 \\
\text { years }\end{array}$ & Female & 0.5 & $\begin{array}{l}\text { Classic } \\
\text { PTC }\end{array}$ \\
\hline MNG + PTC_9 & $\begin{array}{c}65 \\
\text { years }\end{array}$ & Male & $\begin{array}{c}0.3 \\
\text { (multifocal) }\end{array}$ & $\begin{array}{c}\text { Classic } \\
\text { PTC }\end{array}$ \\
\hline MNG + PTC_10 & $\begin{array}{c}62 \\
\text { years }\end{array}$ & Female & 1.0 & $\begin{array}{c}\text { Classic } \\
\text { PTC }\end{array}$ \\
\hline MNG + PTC_11 & $\begin{array}{c}57 \\
\text { years }\end{array}$ & Female & 1.4 & FV-PTC \\
\hline MNG + PTC 12 & $\begin{array}{c}53 \\
\text { years }\end{array}$ & na & $\begin{array}{c}0.5 \\
\text { (multifocal) }\end{array}$ & $\begin{array}{c}\text { Classic } \\
\text { PTC }\end{array}$ \\
\hline
\end{tabular}

TCV, tall cell variant of PTC; FV-PTC, follicular variant of PTC; na, not available.

malignant tissue (PTC) than the other benign samples (MG) (Figures 2(b) and (c)). The supervised cluster analysis of all 33 samples using the 359-gene set separated the apparently "benign" and "malignant" samples with strong cluster robustness ( 0.991 for the "benign samples" cluster and 0.986 for the "malignant samples" cluster, $\mathrm{R}$ index 0.987) (Figure 2(c)). No differences were seen between hyperplastic thyroid samples derived from patients with classic PTC and those with PMC.

Evaluating these 359 genes, we identified only a limited set of 30 genes more than 2-fold differentially expressed between the two groups. Among these, $C D C 42$ (3.49-fold, $\mathrm{p}=0.0014)$, GADD45B (4.01-fold, $\mathrm{p}=0.0029$ ), KLF9 (3.33-fold, $\mathrm{p}=0.0028$ ), $P B X 3$ (3.32-fold, $\mathrm{p}=$ 0.0038 ) and SLC34A2 (3.11-fold, $\mathrm{p}=0.0011$ ) were the most strongly over-expressed in the HN + PTC group compared to the MNG group.

\section{Discussion}

In general, thyroid hyperplasia is believed to be polyclonal while neoplastic thyroid diseases are monoclonal. However, it is known that papillary thyroid carcinoma occurs frequently as multifocal disease and Shattuck et al. showed that these multiple foci PTC's are of different
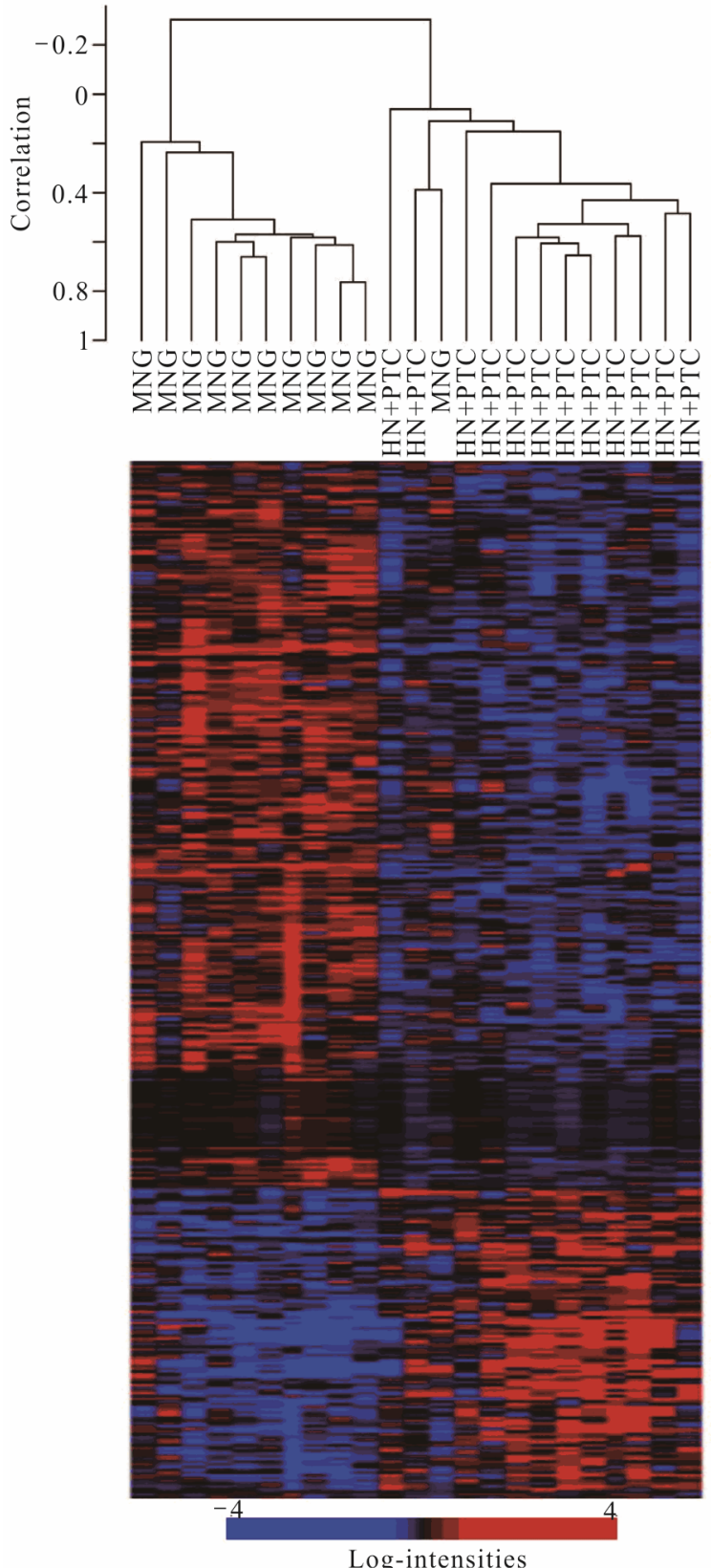

Figure 1. Supervised cluster analysis of expression data from non-malignant hyperplastic thyroid cells from multinodular goitre samples (MNG) and those from HN + PTC samples (HN + PTC) based on a set of 359 genes most significantly differentially regulated between those two groups. Each row in the heat map represents one gene, with red indicating relative over- and blue under-expression for the individual sample (columns).

clonal origin [5], similar to non-neoplastic thyroid hyperplasia [6]. This might indicate that the whole thyroid gland, as a field, might be influenced by factors promoting neoplastic transformation, which becomes enhanced when additional growth stimulating factors are present. If such a field defect existed, then we would expect to find 


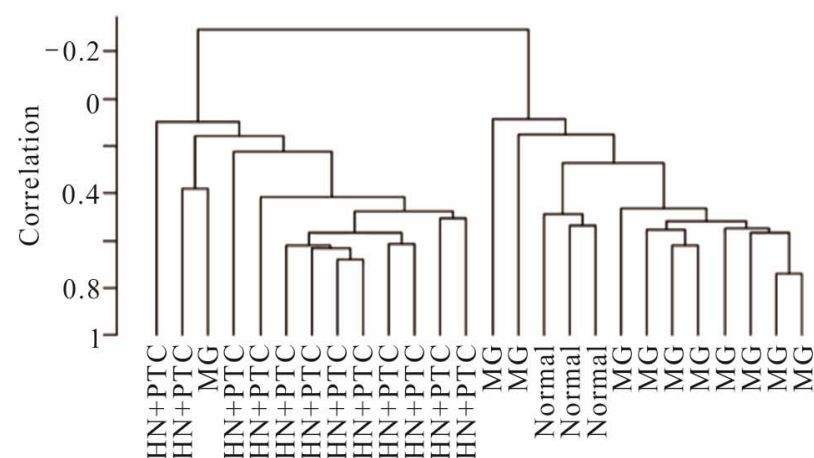

(a)

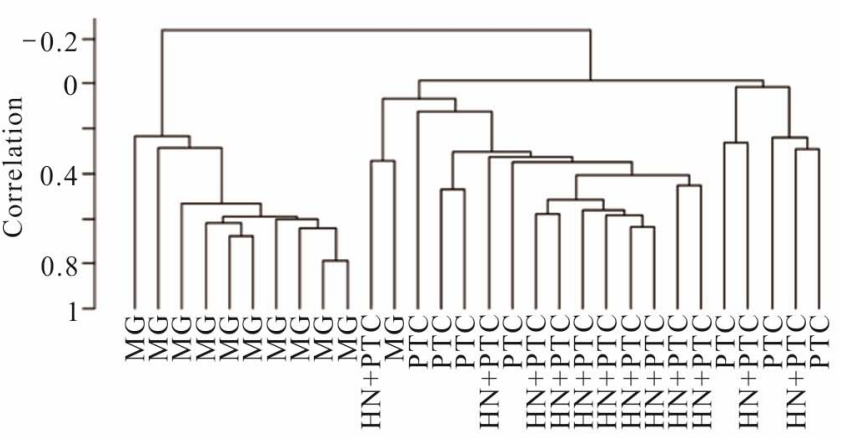

(b)

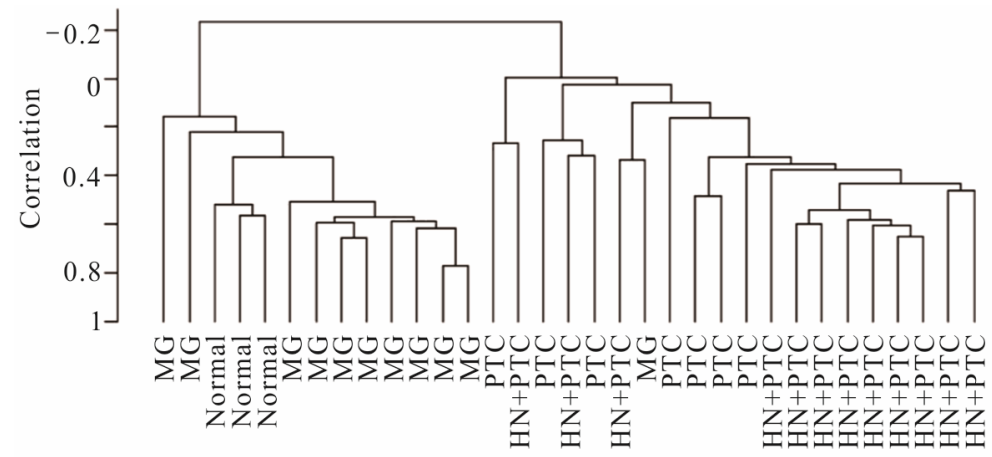

(c)

Figure 2. Supervised cluster analysis utilizing a series of 359 genes found differentially expressed between the MNG and HN + PTC groups. New samples, 3 normal thyroid samples (a) or 7 PTC samples (b) clustered according to their similarities to the HN + PTC or MG group. Clustering of all 33 samples according to the set of 359 genes that best differentiated the two goiter groups (MG and HN + PTC) separated the samples into "benign" (MG and normal) and "malignant" (PTC and HN + PTC) samples (c).

a unique gene expression profile already existing in the non-malignant thyroid tissue that differentiates the hyperplastic thyroid epithelial cells of MG with unsuspected PTC from MG without PTC [10-12]. Our global gene expression analysis of these two groups of goiters (MNG and HN + PTC) suggested that indeed environmental or genetic factors exist that might alter the overall gene expression profile in the thyroid epithelial cells making them susceptible to further transformation. To this end, $C D C 42$ that showed very high over-expression in HN + PTC compared to MNG merits further discussion. CDC42 is activated by some environmental factors such as gamma-radiation or UVB-light $[13,14]$. None of our patients had a documented history of medical or obvious environmental exposure to radiation. However, in this regard, it is important to acknowledge that, for this study, we cannot account for all environmental factors, like exposure to terrestrial radiation (radon) or medical $\mathrm{x}$-rays. The association between UVB-irradiation and thyroid cancer susceptibility is purely hypothetical but intriguing. Grant et al. recently showed that thyroid cancer is among the set of 9 cancers with mortality rates significantly correlated with residence at a particular latitude, an index of solar UVB levels [15].
Considering the overlap between the MNG and HN + PTC groups in unsupervised clustering approaches (data not shown) and the limited set of genes that showed high differential expression (i.e. more than 2-fold), another hypothesis might be that the neoplastic transformation is a "normal" process of the aging thyroid epithelial cell, promoted by the growth stimulating factors associated with thyroid hyperplasia. Interestingly, our HN + PTC group was, on average, almost 6 years older than the MNG group, although this difference does not reach statistical significance. If this is true, it is tantalizing to postulate that in all patients with MG, this field defect may exist and that the hyperplastic thyroid epithelial cells will eventually transform given infinite time. As for the clinical consequence, we would have to propose that at some point, potentially all patients with a multi-nodular thyroid disease will develop thyroid cancer, if they lived an infinite time.

Taken together, our observations suggest that several genes, while already dysregulated in non-malignant tissue, might somehow predispose to PTC formation given the "right" downstream genetic/epigenetic alterations and/or environmental exposures. While further research is required to clarify the mechanism and functional rele- 
vance, we believe that the elucidation of these concepts of field defect/effect and field cancerization in thyroid disease warrants further research since the outcome might have substantial impact on our interventional approach for multinodular goiter.

\section{REFERENCES}

[1] L. Hegedus, "Clinical Practice. The Thyroid Nodule," New England Journal of Medicine, Vol. 351, No. 17, 2004, pp. 1764-1771.

[2] M. Piersanti, S. Ezzat and S. L. Asa, "Controversies in Papillary Microcarcinoma of the Thyroid," Endocrine Pathology, Vol. 14, No. 3, 2003, pp. 183-191. doi:10.1007/s12022-003-0011-5

[3] P. P. Gandolfi, A. Frisina, M. Raffa, F. Renda, O. Rocchetti, C. Ruggeri and A. Tombolini, "The Incidence of Thyroid Carcinoma in Multinodular Goiter: Retrospective Analysis,” Acta Biomed Ateneo Parmense, Vol. 75, 2004, pp. 114-117.

[4] A. McCall, H. Jarosz, A. M. Lawrence and E. Paloyan, "The Incidence of Thyroid Carcinoma in Solitary Cold Nodules and in Multinodular Goiters,” Surgery, Vol. 100, No. 6, 1986, pp. 1128-1132.

[5] T. M. Shattuck, W. H. Westra, P. W. Ladenson and A. Arnold, "Independent Clonal Origins of Distinct Tumor Foci in Multifocal Papillary Thyroid Carcinoma," New England Journal of Medicine, Vol. 352, No. 23, 2005, pp. 2406-2412. doi:10.1056/NEJMoa044190

[6] H. Studer and M. Derwahl, "Mechanisms of Nonneoplastic Endocrine Hyperplasia-A Changing Concept: A Review Focused on the Thyroid Gland," Endocrine Reviews, Vol. 16, No. 4, 1995, pp. 411-426. doi:10.1210/er.16.4.411

[7] F. Weber, S. Lei, M. A. Aldred, C. Morrison, M. D. Ringel, M. Saji, F. Schuppert, A. Frilling, C. E. Broelsch and C. Eng, "Genetic Classification of Benign and Malignant Thyroid Follicular Neoplasoa Based on a 3-Gene Combination," Journal of Clinical Endocrinology and Metabolism, Vol. 90, No. 5, 2005, pp. 2512-2521. doi:10.1210/jc.2004-2028

[8] G. W. Wright and R. M. Simon, “A Random Variance Model for Detection of Differential Gene Expression in Small Microarray Experiments,” Bioinformatics, Vol. 19, No. 18, 2003, pp. 2448-2455. doi:10.1093/bioinformatics/btg345

[9] L. M. McShane, M. D. Radmacher, B. Freidlin, R. Yu, M. C. Li and R. Simon, "Methods for Assessing Reproducibility of Clustering Patterns Observed in Analyses of Microarray Data," Bioinformatics, Vol. 18, No. 11, 2002, pp. 1462-1469. doi:10.1093/bioinformatics/18.11.1462

[10] N. Ahuja and J. P. Issa, “Aging, Methylation and Cancer,” Histology and Histopathology, Vol. 15, No. 3, 2000, pp. 835-842.

[11] B. J. Braakhuis, M. P. Tabor, J. A. Kummer, C. R. Leemans and R. H. Brakenhoff, "A Genetic Explanation of Slaughter's Concept of Field Cancerization: Evidence and Clinical Implications,” Cancer Research, Vol. 63, No. 8, 2003, pp. 1727-1730.

[12] C. Hafner, R. Knuechel, R. Stoehr and A. Hartmann, "Clonality of Multifocal Urothelial Carcinomas: 10 Years of Molecular Genetic Studies," International Journal of Cancer, Vol. 101, No. 1, 2002, pp. 1-6. doi:10.1002/ijc.10544

[13] M. Seo, C. H. Cho, Y. I. Lee, E. Y. Shin, D. Park, C. D. Bae, J. W. Lee, E. S. Lee and Y. S. Juhnn, “Cdc42-Dependent Mediation of UV-Induced p38 Activation by G Protein Betagamma Subunits," Journal of Biological Chemistry, Vol. 279, No. 17, 2004, pp. 17366-17375. doi:10.1074/jbc.M312442200

[14] O. A. Coso, M. Chiariello, J. C. Yu, H. Teramoto, P. Crespo, N. Xu, T. Miki and J. S. Gutkind, "The Small GTP-Binding Proteins Rac1 and Cdc42 Regulate the Activity of the JNK/SAPK Signaling Pathway," Cell, Vol. 81, No. 7, 1995, pp. 1137-1146. doi:10.1016/S0092-8674(05)80018-2

[15] W. B. Grant, “An Ecologic Study of Cancer Mortality Rates in Spain with Respect to Indices of Solar UVB Irradiance and Smoking," International Journal of Cancer, Vol. 120, 2007, pp. 1123-1128. doi:10.1002/ijc.22386 